\title{
Appropriate footwear and orthoses are essential components in the management of the foot at risk of ulceration in leprosy
}

\author{
Karthikeyan Govindasamy ${ }^{\mathrm{a}, \mathrm{b}}$ \& Sathish Kumar Paul ${ }^{\mathrm{c}}$ \\ ${ }^{a} P h D$ Scholar, Warwick Centre for Global Health, Warwick Medical School, \\ University of Warwick, Coventry CV4 7AL, UK \\ ${ }^{\mathrm{b}}$ Research Coordinator, The Leprosy Mission Trust India, New Delhi, India \\ ${ }^{\mathrm{c}}$ Head-Research, Schieffelin Institute of Health Research \& Leprosy Centre, \\ Karigiri, Vellore, India
}

Submitted 17 September 2021; Accepted 30 November 2021

\begin{abstract}
Summary Ulcers are a serious complication and a common cause of morbidity in leprosy. The exact roles of impairments and distorted mechanics of the foot are not fully understood in the development of ulcers in patients with anaesthetic feet. A simple biomechanical evaluation of the foot along with the routine neurological assessment helps to identify feet at risk for developing an ulcer and also to prescribe appropriate orthoses, which are inserts designed to improve biomechanical function, encourage proper joint alignment and protect the foot. The orthotic intervention along with protective footwear offloads the peak plantar pressure sites of the foot, preventing ulceration. The provision and use of foot orthoses have generally been limited to tertiary leprosy referral centres. Advances in technology have made the fabrication of orthoses more rapid and precise, enhancing user acceptance and adherence. Effort should be made to provide simple orthoses that are easy to fabricate and effective in preventing plantar ulcers in leprosy, in the community health setting.
\end{abstract}

Keywords: Anesthetic foot, footwear, ulcer, foot impairment, leprosy

\section{Introduction}

The posterior tibial nerve is frequently affected in leprosy ${ }^{1,2}$ leading to loss of sensation and sweating, and intrinsic muscle paralysis in the foot, predisposing to ulcer formation. ${ }^{3}$ Recurrent ulcers can lead to shortening and amputation of the affected limb ${ }^{4}$ and delayed or non-healing ulcers can transform into squamous cell carcinoma. ${ }^{5}$ Therefore, prevention of ulcers is critical to preventing disability. The actual burden of disability, including foot ulcers, due to leprosy is not known. ${ }^{6}$ Over $42 \%$ (3088/7359) of admissions and over 55\% (97561/174559) of bed-days utilized were for ulcer care at tertiary hospitals of The Leprosy Mission Trust India (TLMTI)

Correspondence to: Karthikeyan Govindasamy (e-mail: karthikot@hotmail.com) 
and Schieffelin Institute of Health Research \& Leprosy Centre (SIHRLC), Karigiri during the year 2019 alone. ${ }^{7,8}$

Although protective footwear can reduce the prevalence of ulcers, ${ }^{9-11}$ the role of orthoses in protective footwear in preventing ulcers has not been satisfactorily studied. ${ }^{12}$ The consensus statement on prevention of disability in leprosy emphasises the accessibility of footwear with soft insoles and orthoses to all those with anaesthetic feet. ${ }^{13}$ An orthosis is a device designed to improve biomechanical function, encourage proper joint alignment or to protect an existing limb.

\section{Importance of podiatry assessment}

There is a wide variation in the alignment and flexibility of the foot in the general population. ${ }^{14}$ This variation in general is not a concern but for those with loss of sensation and intrinsic muscle paralysis in the foot such as in leprosy, it can increase the risk of ulceration even with normal walking, by increasing the peak plantar pressure at vulnerable sites for ulcers such as the metatarsal heads. ${ }^{15,16}$ This natural variation is perhaps a reason why not all patients with loss of sensation in the foot develop ulcers, ${ }^{17,18}$ and we do not have clinical tools that can predict the feet at the risk of ulcer development. ${ }^{15}$ Podiatry assessment is necessary to understand foot function and to plan foot orthoses to off-load the at risk sites for ulceration. While footwear with a micro-cellular rubber (MCR) insole with a shore value of 15-20, can increase the contact surface of the foot and reduce plantar pressure, ${ }^{19,20}$ its ability to reduce peak pressures at the risk sites for ulcers is not known. Studies on commonly used insole materials have shown that optimizing the stiffness of materials promotes the distribution of externally applied forces evenly, thereby reducing the peak pressures at the risk sites. ${ }^{21}$ Paul et al. demonstrated that materials such as Ethylene Vinyl Acetate (EVA) which is more rigid than MCR could provide greater stability and be a good alternative for MCR insoles and orthoses. $^{22}$

\section{Foot orthoses to off-load pressure on at risk sites for ulcers}

The evidence from diabetic foot care has shown that therapeutic footwear and/or orthoses are effective in reducing peak plantar pressure, thus reducing the risk of first and recurrent ulcers. ${ }^{23-25}$ Foot orthoses are custom-made and fall into two broad categories, accommodative and functional. Accommodative orthoses are made of soft materials to provide cushioning to the foot and shock absorption during the gait. Functional orthoses are made of more rigid materials and aim to re-align the foot to achieve the normal weight bearing position. ${ }^{26}$ For example, Figure 1 shows a simple accommodative orthosis for the left foot that can be provided to patients with 'low-arch'. The common orthoses provided in leprosy for a specific foot problem are shown in Table 1 and Figures 2 to 5 . They can either be provided as an individual orthosis or in combination depending on the foot problem. In one study, foot orthoses were inserted over the MCR insole to accommodate (off-load) the ulcer area, to promote ulcer healing; over a period of 7-month, 57\% of ulcers in the experimental group healed, as compared to $12.5 \%$ of ulcers in the control group who received only MCR footwear. ${ }^{27}$ It is important to note that just as an ill-fitting shoe can have a lasting impact on the biomechanics of the foot, ${ }^{28}$ an imprecise orthosis can also worsen foot mechanics.

Functional orthoses aim to re-align the subtalar joint in the neutral position during walking, to facilitate a normal weight bearing pattern. ${ }^{29}$ Cast measurement in a functional weight bearing position with the subtalar joint in the neutral position is ideal for prescribing a 


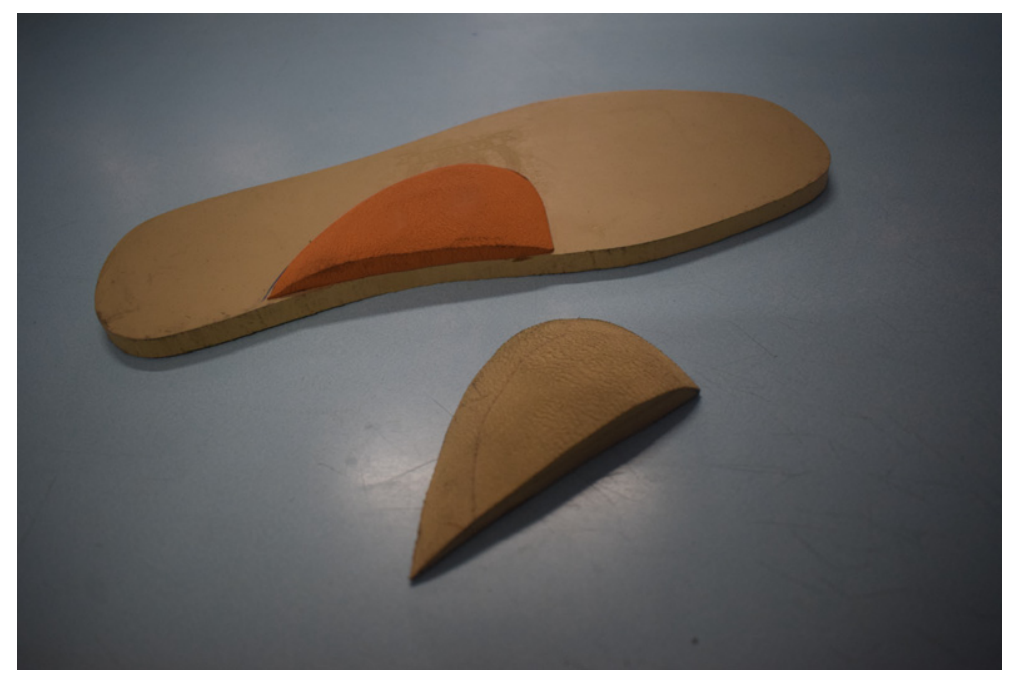

Figure 1. Accommodative orthosis, which fits under and supports the medial arch of the foot; the illustration is for the left foot.

Table 1. Foot problems and common accommodative orthoses used in leprosy

\begin{tabular}{ll}
\hline Foot problem & Accommodative orthosis \\
\hline Pronated foot & Hathi Pad or Cobra Pad (Figure 2) \\
Supinated foot & Tarsal Platform (Figure 3) \\
Ulcer/Callous in 1st MTH & 'Wing' Plantar Metatarsal Pad (Figure 4) \\
Ulcer/Callous in the 3rd MTH & 'U'Plantar Metatarsal Pad (Figure 5) \\
\hline
\end{tabular}

functional orthosis. ${ }^{30}$ Technicians require high precision and accuracy to fabricate functional orthoses. Although the subtalar neutral position is the reference point for casting, the reliability of maintaining the foot in the subtalar neutral position while casting has been questioned. ${ }^{31,32}$ With recent advances in technology it is possible to modify the subtalar joint position virtually. Figure 6 shows the evaluation of the subtalar joint position in a patient through a laser scanner. The custom-made insoles with integral orthoses using such techniques have helped prevent ulcer recurrence compared to the conventional MCR insoles in leprosy patients. ${ }^{33}$ Figure 7 shows a functional orthosis made by a computerized fabrication method.

The most common method adopted by technicians to measure foot alignment in patients before providing footwear is to get the foot dimensions in static stance. ${ }^{34}$ This method has been useful to prescribe footwear to a patient with intact foot contours. ${ }^{35}$ It has been challenging, however, for footwear technicians and health staff to assess and provide protective footwear with the required orthoses to anaesthetic feet with abnormal mechanics. ${ }^{36}$

The rationale for prescribing footwear with orthoses in anaesthetic feet with varied foot alignment has often been unclear to health care workers and patients. Ignorance about appropriate footwear and orthoses is a common reason for non-compliance. ${ }^{37}$ Studies have demonstrated that evaluating the foot in both static and kinetic stance have facilitated in assessing the abnormal variations and asymmetries of the foot. Assessing the subtalar joint range of movement, the rearfoot and forefoot alignments, first ray position and the 


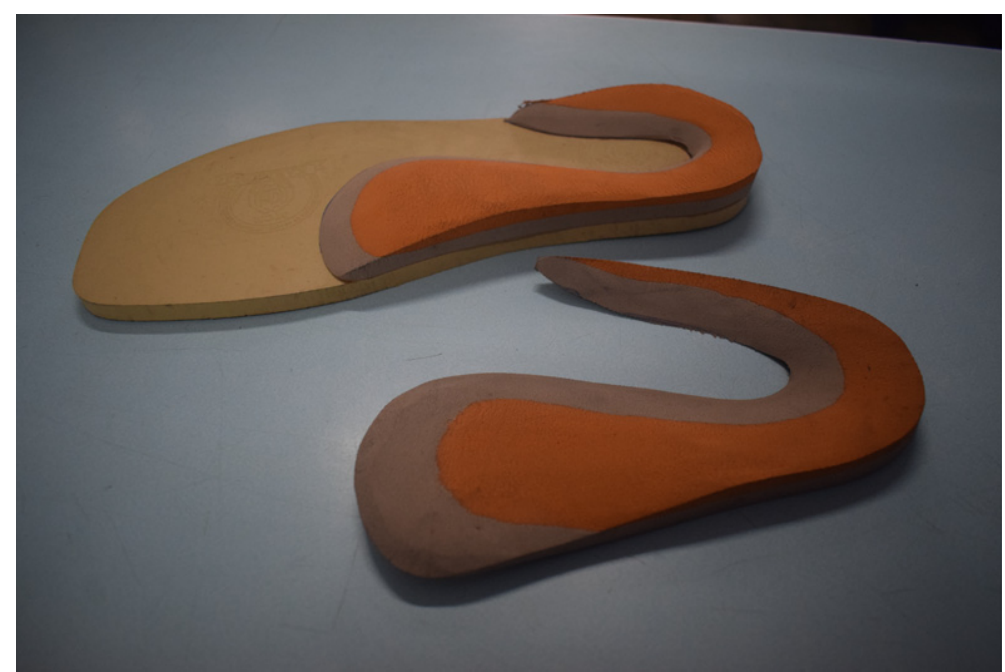

Figure 2. Hathi or Cobra pad, which fits under and supports the medial arch and heel of the foot; the illustration is for the right foot.

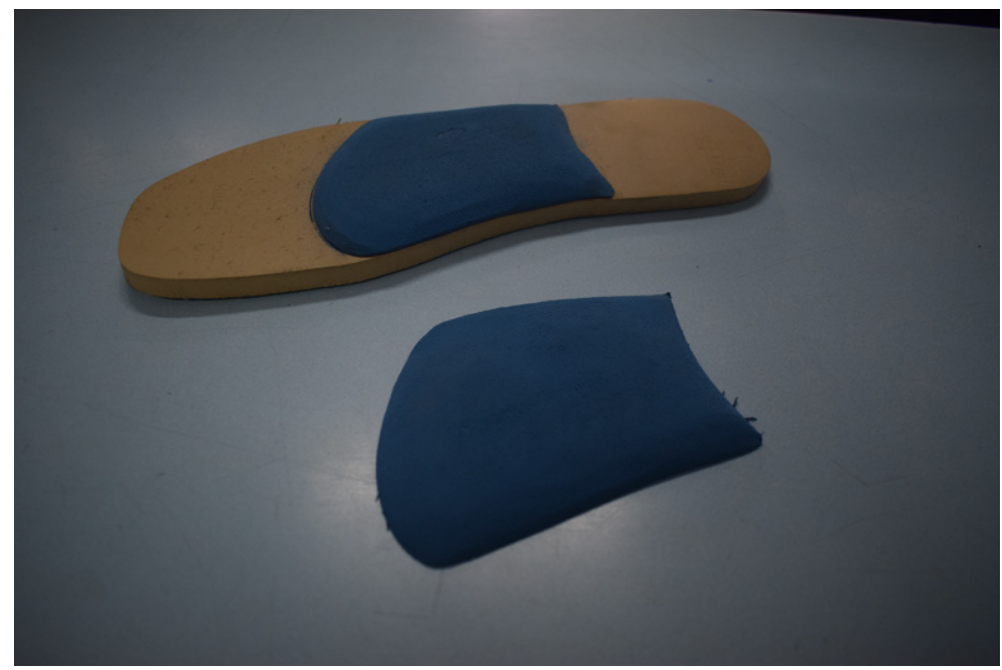

Figure 3. Tarsal platform which fits under and supports the mid-foot (tarsal bones); the illustration is for the right foot.

1st metatarsophalangeal joint position is essential in understanding the foot biomechanics and in prescribing appropriate orthoses. ${ }^{38}$ Cross and Lehman proposed a Simple Semantic Classification (SSC) to identify the foot at risk for ulcer, which is reliable and valid, and could be effectively used by health care workers in peripheral health centres in a resource limited setting with minimal training. ${ }^{39}$ The use of this simple algorithm for prescribing footwear and orthoses for patients in resource limited settings could help in effective management of the foot with loss of sensation. ${ }^{29,40,41}$ 


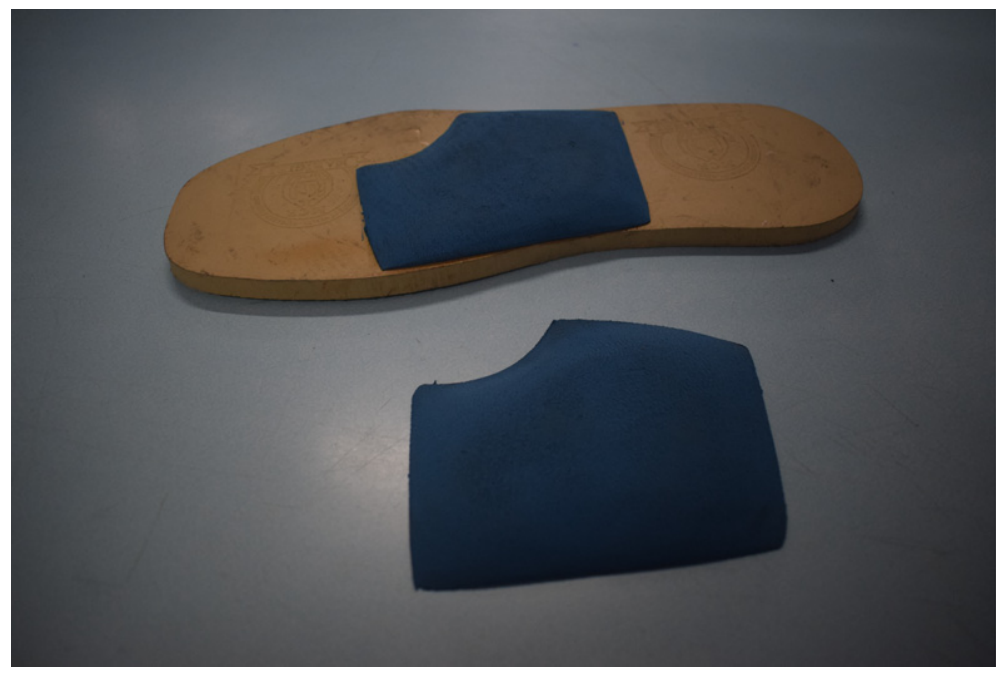

Figure 4. Wing Plantar Metatarsal Pad (PMP) which fits under the mid foot with cut-out to off-load the ulcer area; the illustration is for the right foot with an ulcer over the fifth meta-tarsal head.

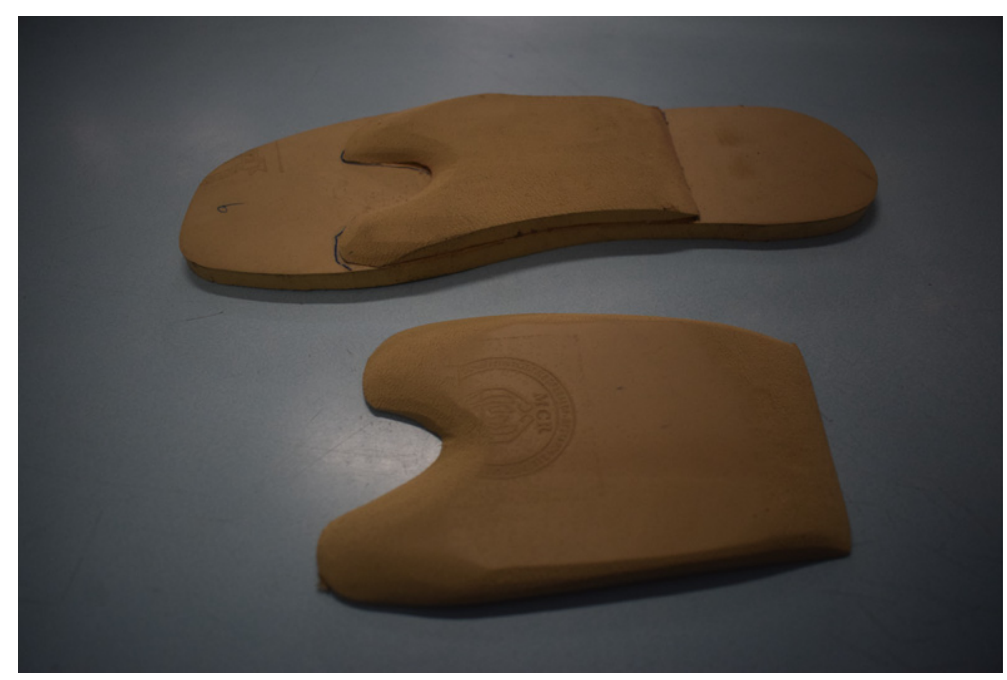

Figure 5. U Plantar Metatarsal Pad (PMP) which fits under mid foot with cut-out to off-load the ulcer area; the illustration is for the right foot with an ulcer over third meta-tarsal head.

Leprosy patients are also looking for newer footwear designs. ${ }^{42}$ Gupta et al. suggested that acceptability would improve when footwear is provided with newer designs, varied colour and is of a good fit. ${ }^{43}$

\section{Recent advances in footwear and orthosis fabrication}

With the recent advances in technology, the peak plantar pressures at risk sites can be effectively identified using tactile sensors. ${ }^{40,44}$ Based on the joint alignment of the foot identified 


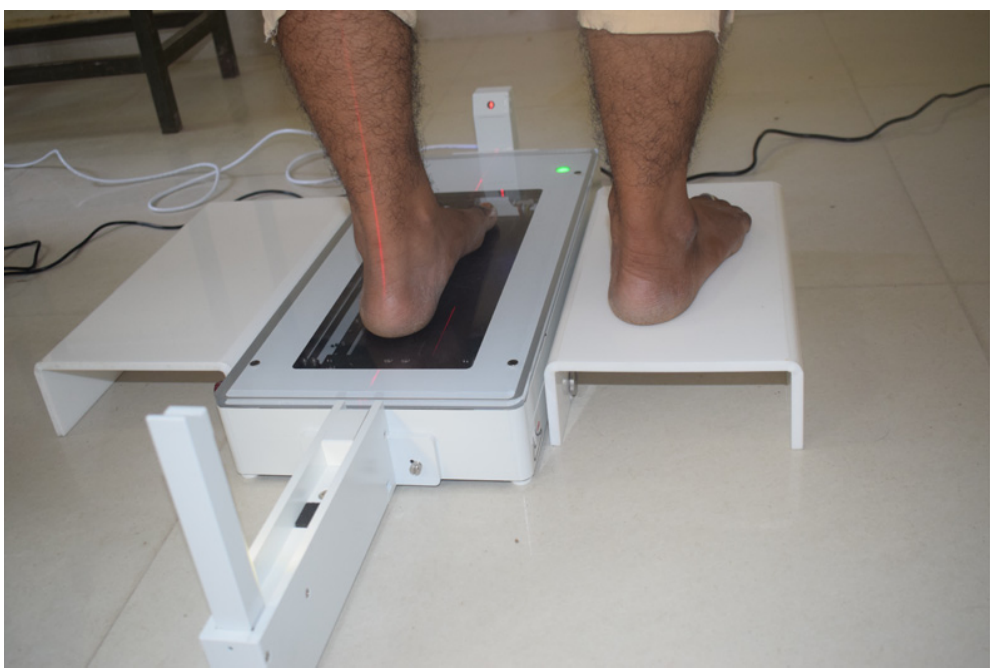

Figure 6. Evaluation of the subtalar joint position in a patient through a laser scanner.

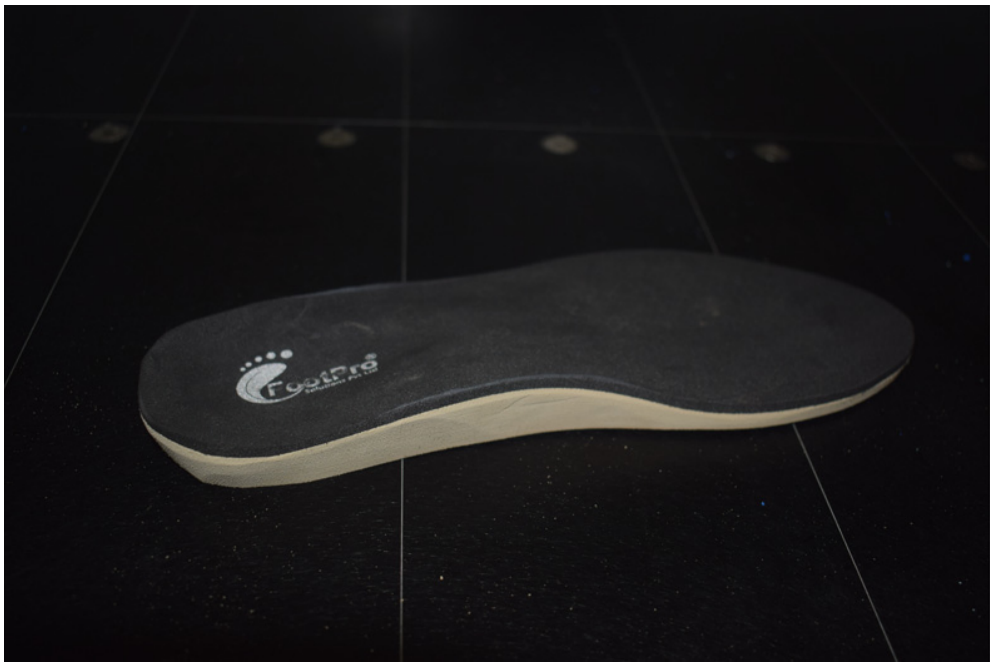

Figure 7. Functional orthosis made by a computerized fabrication method.

through computerized scanning, orthoses can be either manufactured through computerized $3 \mathrm{D}$ printing or milling technology. ${ }^{33}$ While the newer technologies are attractive, providing simple and effective orthoses at the peripheral level is needed and effort should be made to include the provision of basic accommodative orthoses such as the tarsal platform, plantar metatarsal pads and medial arch support in leprosy programs to improve the effectiveness of the footwear provided. Bulk production of ready to fit orthoses could help reduce the burden on the health care worker in peripheral settings. Availability of cost effective rigid and semi rigid, ready to fit anti-pronatory and supinatory orthoses for different foot sizes could help patients in remote locations. ${ }^{45}$ 


\section{Conclusion}

Limited evidence shows that appropriate footwear and orthoses are effective in reducing peak plantar pressures and thereby ulcers in anaesthetic feet. However, the use of these interventions has been restricted to referral centres due to a lack of personnel for fabrication at the field level. Advances in technology will help in customizing the fabrication of orthoses and make it cost effective. Viable and cost-effective options could be made available for the health staff in a virtual medium to customize and visualize the orthosis before fabrication. The computerized fabrication of orthoses could become an ideal method in the future. Meanwhile, the bulk production of ready to fit orthoses can meet the immediate needs at peripheral health centres.

\section{Ethics approval}

Not required.

\section{Competing interests}

The authors have no competing interests.

\section{Funding}

This research was funded by the National Institute for Health Research (NIHR: 200132) using UK Aid from the UK Government to support global health research. KG is also funded by The Leprosy Mission Trust India. SKP is funded by Schieffelin Institute of Health Research $\&$ Leprosy Centre, Karigiri, Vellore, India. The views expressed in this publication are those of the author(s) and not necessarily those of the NIHR or the UK Department of Health and Social Care or authors affiliated institution.

\section{Authors' contributions}

KG and SKP: contributed to the development and editing of the manuscript.

\section{Acknowledgements}

We acknowledge the support and contribution of other members of the NIHR RIGHT grant team including Jo Sartori (University of Birmingham) and Sopna Choudhury. We would also like to acknowledge Dr Jerry Joshua, Director, Schieffelin Institute of Health Research \& Leprosy Centre and Dr Joydeepa Darlong, Head-Knowledge Management, The Leprosy Mission Trust India for their continued support for this work.

\section{References}

1 Van Brakel WH, Khawas IB. Nerve damage in leprosy: an epidemiological and clinical study of 396 patients in west Nepal—Part 1. Definitions, methods and frequencies. Lepr Rev, 1994; 65: 204-221.

2 Saunderson P, Gebre S, Desta K, Byass P. The ALERT MDT Field Evaluation Study (AMFES): a descriptive study of leprosy in Ethiopia. Patients, methods and baseline characteristics. Lepr Rev, 2000; 71: 273-284.

3 Srinivasan H. In: Srinivasan H (ed.), Prevention of Disabilities in Patients with Leprosy: a Practical Guide. Geneva: World Health Organization, 1993; p. 140.

4 Virmond M. Amputations in leprosy. Lepr Rev, 2007; 78: 85-87.

5 Richardus JH, Smith TC. Squamous cell carcinoma in chronic ulcers in leprosy: a review of 38 consecutive cases. Lepr Rev, 1991; 62: 381-388.

6 Meima A, van Veen NH, Richardus JH. Future prevalence of WHO grade 2 impairment in relation to incidence trends in leprosy: an exploration. Trop Med Int Health, 2008; 13(2): 241-246.

7 SHIRLC. Activity Report - 2019. Vellore, India: Schieffelin Institute of Health - Research \& Leprosy Centre, Karigiri, 2019. 
8 TLMTI. 2019 Annual Report. New Delhi, India: The Leprosy Mission Trust India, 2019.

9 Ebenso J, Muyiwa LT, Ebenso B. Self care groups and ulcer prevention in Okegbala, Nigeria. Lepr Rev, 2009; 80(2): 187-196.

10 Chakraborty A, Sundar Rao PSS, Mahato M. Self-care programme to prevent leprosy-related problems in a leprosy colony in Champa, Chattisgarh. Indian J Lepr, 2006; 78(4): 319-327.

11 Cross H. The prevention of disability as a consequence of leprosy. Lepr Rev, 2015; 86: 208-212.

12 Reinar LM, Forsetlund L, Lehman LF, Brurberg KG. Interventions for ulceration and other skin changes caused by nerve damage in leprosy. Cochrane Database Syst Rev, 2019; 7(7): CD012235.

13 Saunderson P. Consensus statement on prevention of disability. Lepr Rev, 2006; 77: 387-395.

14 Quinn G. Normal genetic variation of the human foot: Part 2: population variance, epigenetic mechanisms, and developmental constraint in function. J Am Podiatr Med Assoc, 2012; 102(2): 149-156.

15 Cross H, Rendall G. An investigation of common forms of pathomechanical foot function and their association with force related variables and ulceration amongst people with loss of sensation due to leprosy. Br J Podiatry, 2007; 10(4): 154-161.

16 Tashiro S, Gotou N, Oku Y, Sugano T, Nakamura T, Suzuki H et al. Relationship between plantar pressure and sensory disturbance in patients with hansen's disease-preliminary research and review of the literature. Sensors, 2020; 20(23): 6976.

17 Feenstra W, Van de Vijver S, Benbow C, Amenu A, Saunderson P. Can people affected by leprosy at risk of developing plantar ulcers be identified? A field study from central Ethiopia. Lepr Rev, 2001; 72(2): 151-157.

18 Bhatia M, Patil M. New on-line parameters for analysis of dynamic foot pressures in neuropathic feet of Hansen's disease subjects. J Rehab Res Dev, 1999; 36: 264-272.

19 Ward D. Footwear in leprosy. Lepr Rev, 1962; 33: 94-105.

20 Karat S. Preventive rehabilitation in leprosy. Lepr Rev, 1968; 39(1): 39-44.

21 Chatzistergos PE, Naemi R, Healy A, Gerth P, Chockalingam N. Subject specific optimisation of the stiffness of footwear material for maximum plantar pressure reduction. Ann Biomed Eng, 2017; 45(8): 1929-1940.

22 Paul S, Kumar DP, Siva B. Material analysis for therapeutic insoles-A short report. Lepr Rev, 2021; 92: 75-81.

23 van Netten JJ, Sacco IC, Lavery LA, Monteiro-Soares M, Rasmussen A, Raspovic A et al. Treatment of modifiable risk factors for foot ulceration in persons with diabetes: a systematic review. Diabetes/Metab Res Rev, 2020; 36: e3271.

24 Albert S, Rinoie C. Effect of custom orthotics on plantar pressure distribution in the pronated diabetic foot. $J$ Foot Ankle Surg: Off Publ Am Coll Foot Ankle Surg, 1994; 33(6): 598-604.

25 van Netten JJ, Raspovic A, Lavery LA, Monteiro-Soares M, Rasmussen A, Sacco ICN et al. Prevention of foot ulcers in the at-risk patient with diabetes: a systematic review. Diabetes Metab Res Rev, 2020; 36(Suppl 1): e3270.

26 Kennedy S. Material choices in foot orthotic design. The O\&P Edge, 2008. https://tinyurl.com/s926xbm (accessed 13 January 2020).

27 Cross H, Sane S, Dey A. The efficacy of podiatric orthoses as an adjunct to the treatment of plantar ulceration in leprosy. Lepr Rev, 1995; 66(2): 144-157.

28 Arnold M. The biomechanical implications of wearing ill-fitting shoes. The Foot, 2008; 18(4): 183.

29 Cross H. Foot orthotic therapy. Surg Reconstr Rehabilitation Lepr Other Neuropathies, 2004; 243.

30 Guldemond NA, Leffers P, Sanders AP, Emmen H, Schaper NC, Walenkamp GH. Casting methods and plantar pressure: effects of custom-made foot orthoses on dynamic plantar pressure distribution. J Am Podiatr Medi Assoc, 2006; 96(1): 9-18.

31 McPoil T, Cornwall MW. Relationship between neutral subtalar joint position and pattern of rearfoot motion during walking. Foot Ankle Int, 1994; 15(3): 141-145.

32 Chuter V, Payne C, Miller K. Variability of neutral-position casting of the foot. J Am Podiatr Med Assoc, 2003; 93(1): 1-5.

33 Govindasamy K, Raja NR, Gupta P, Anand G, Das P, Darlong F et al. Computer assisted customized footwear and traditional micro-cellular rubber (MCR) footwear to reduce recurrence of ulcer for patients with loss of sensation due to leprosy. Lepr Rev, 2020; 91(4): 383-392.

34 Patil K, Babu T, Oommen P, Srinivasan H. Foot pressure measurement in leprosy and footwear design. Indian J Lepr, 1986; 58(3): 357-366.

35 Linda FL, Mary JG, Bolton L. Use Protective Footwear. 2021: [1-12 pp]. Available from: https://www.leprosy .org/wp-content/uploads/2015/06/ALM-10Steps-Step10-021816.pdf.

36 Mrdjenovich DE. Off-loading practices for the wounded foot: concepts and choices. J Am Coll Certified Wound Specialists, 2010; 2(4): 73-78.

37 Chantelau E, Haage P. An audit of cushioned diabetic footwear: relation to patient compliance. Diabetic Med, 1994; 11(1): 114-116.

38 Valmassy RL. Clinical Biomechanics of the Lower Extremities: Mosby Incorporated. 1996. 
39 Cross HA, Lehman L. The validity and reliability of a simple semantic classification of foot posture. Lepr Rev, 2008; 79(4): 416-424.

40 Paul MSK, Kumar DP, Govindasamy K. Physical rehabilitation in leprosy, Chapter 4.3. In: Scollard DM, Gillis TP (eds), International Textbook of Leprosy. 2019. http://www.internationaltextbookofleprosy.org; 26 January.

41 Dahmen R, Haspels R, Koomen B, Hoeksma AF. Therapeutic footwear for the neuropathic foot: an algorithm. Diabetes Care, 2001; 24(4): 705-709.

42 Lal V, Sarkar D, Das S, Mahato M, Srinivas G. A study to assess the usage of MCR footwear in West Bengal, India. Lepr Rev, 2015; 86(3): 273-277.

43 Gupta P, Govindasamy K, Nathan JR. Footwear for the person with an anesthetic foot: what options are available?. Lepr Rev, 2017; 88(2): 265-269.

44 Paul MS, Siva B. Peak plantar pressure analysis using customized tactile sensory feedback system-A short report. Lepr Rev, 2021; 92(1): 82-87.

45 Nagano H, Begg RK. Shoe-insole technology for injury prevention in walking. Sensors, 2018; 18(5): 1468. 